\title{
The aprosodias: further functional-anatomical evidence for the organisation of affective language in the right hemisphere
}

\author{
PHILIP B GORELICK, ${ }^{*}$ ELLIOTT D ROSS $\dagger$
}

From the Department of Neurology* (Stroke Service), the Michael Reese Hospital and Medical Center, and the Departments of Neurology and Psychiatry $\dagger$ (Behavioral Neurology Service), the University of Texas Health

Science Center at Dallas, USA

SUMMARY Fourteen right-handed patients with right hemispheric strokes were examined for disorders of affective language in order to further define the clinical-anatomical correlates of the aprosodias. A bedside evaluation strategy and CT scan mappings were utilised to make these comparisons. There were six patients with motor aprosodia, one with global aprosodia, two with conduction aprosodia, one with sensory aprosodia, one with transcortical sensory aprosodia, one with pure affective deafness and two with normal examinations of affect. Functional-anatomical correlations were consistent with those predicted previously. Recovery of affective language function in selected cases was characterised by improvements in affective-prosodic repetition and/or evolution into other aprosodic subtypes. Our results lend further support to the hypothesis that the organisation of affective language in the right hemisphere mirrors that of propositional language in the left hemisphere.

Because the left hemisphere plays a major role in the neural processes governing the production and comprehension of propositional language, it has been designated as the "dominant" hemisphere. The propositional attributes of language are principally concerned with lexicon, grammar and articulation. However, there are other features of speech beyond lexicon, grammar and articulation, subsumed under the term prosody, that involve, for example, melody, pauses, timing, stress, accent and intonation. In addition to clarifying potentially ambiguous syntax and adding pragmatic factors to speech, prosody is also the vehicle by which speakers insert attitudes and emotions into their dialogue. Although HughlingsJackson $^{1}$ recognised the clinical importance of affective communication almost 100 years ago, it was not until the 1940s that a systematic inquiry into pathological disturbances of prosody was first undertaken by Monrad-Krohn. ${ }^{2-5}$ More recently, the neurology of the affective components of language, encompassing attitudes and emotions, has been fur-

Address for reprint requests: Philip B Gorelick, M.D. Department of Neurology, Stroke Service, Michael Reese Hospital and Medical Center, 2900 South Ellis, Chicago, Illinois 60616, USA.

Received 26 November 1985 and in revised form 16 April 1986. Accepted 25 April 1986 ther delineated. ${ }^{6-24}$ Studies by Heilman et al, ${ }^{11}$ Tucker et $a l^{12}$ and Ross et al ${ }^{161719}$ suggest that these particular aspects of language appear to be dominantly governed by the right hemisphere and allow spoken language to acquire affective tone through the use of prosody and gesturing. Without them, the expression and comprehension of affectively charged speech may be seriously impaired. The different syndromes of affective deficits following focal right brain damage have been called aprosodias ${ }^{16}$ and appear to be analogues of the aphasias which follow focal brain damage. Since the concept of aprosodias is relatively new, we decided to study patients with right hemispheric strokes in order to see if we could confirm the initial observations concerning the clinicalanatomical correlates of the various aprosodias. ${ }^{16}$

\section{Patients and methods}

Our study population included 14 right-handed patients with right hemisphere strokes who were hospitalised between October, 1981, and April, 1982, at the Michael Reese Hospital and Medical Center. The patients were evaluated consecutively by PBG who was a stroke fellow at Michael Reese at that time. Patients were examined within 2 weeks of stroke onset except for case 9 in which the initial evaluation was performed 2 months after the acute event. 
event. Subjects that remained hospitalised for physical therapy were assessed serially over the succeeding month.

After undergoing a detailed neurological examination, each subject's affective language and behaviour were tested and tape recorded by PBG utilising the bedside technique developed by Ross. ${ }^{16}$ Four major categories of affective language and behaviour were examined: (1) spontaneous affective-prosody and gesturing, (2) affective-prosodic repetition, (3) affective-prosodic comprehension and (4) comprehension of emotional gesturing.

Spontaneous affective-prosody and gesturing were assessed during casual conversation and upon discussion of emotionally charged events in the patient's life. Observations were made about the affective-prosodic quality of the patient's voice (for example intonation, melody and variability) and any mismatching of the affective components of language to the semantic content. Spontaneous speech was judged to have either normal affective prosody or moderate or severe loss of affective prosody, a judgement similar to the assessment of speech fluency in aphasics. In addition, observations regarding the patient's spontaneous facial and limb gesturing were also noted.

Affective-prosodic repetition was assessed by testing the subject's ability to repeat sentences using the affective components of prosody. Each patient was instructed to repeat a declarative sentence void of emotional elements with the same affective quality conveyed by the examiner. The test sentence "I am going to the movies" was presented with happy, sad, angry, and indifferent tones of voice. The patient's ability to match the examiner's affective quality was judged to be poor, moderate or good. Each subject was also graded in a similar fashion on his ability to sing the test sentence with the same melodic quality conveyed by the examiner.

Affective-prosodic comprehension was assessed by standing behind the patient in order to avoid visual clues. A declarative sentence devoid of emotional words was presented to the patient in differing affective tones, and the subject was asked to identify the projected emotion. The test sentence "I am going to the movies" was presented in happy, angry, sad, surprise, and indifferent tones of voice. After each example the patient was given verbally, using a monotone voice in order to avoid prosodic cueing, five multiple-choice answers (outlined above) of which he was asked to select the one that most closely corresponded to the affective tone conveyed in the sentence. Four or five errors out of five on this test was considered poor comprehension; two or three errors constituted moderate comprehension difficulties while zero or one error was considered "normal".

Comprehension of emotional gesturing was assessed by "pantomiming" a series of emotional gestures involving the face and limbs, in order to produce five different affective states: happiness, anger, sadness, surprise, and indifference. The patients were asked to name or describe the emotion after each gesture. If the patient had difficulty identifying the gesture, five multiple choice answers were provided verbally by the examiner using a monotone voice, and the patient was asked to select one. The same rating scale used for affective-prosodic comprehension was also used for this test.

The tape recordings were reviewed independently by both authors without immediate knowledge of the computed tomographic (CT) scan results or each other's diagnostic conclusions. One of us (EDR) was sent the tape recordings in a completely blind fashion without any clinical information to aid in the assessment of affective prosody. Each category of affective language was graded as either being nor- $\overrightarrow{\widehat{a}}$ mal, abnormal or moderately impaired. Subjects were ${ }^{0}$ assigned to an aprosodia subtype according to the classification of Ross. ${ }^{16}$ The two examiners' results were then compared. Any discrepancies in diagnoses were jointly reviewed, and a consensus diagnosis was reached. Joint arbi- $\rightarrow$ tration was required in only one instance, case 12 . In this $\vec{\Rightarrow}$ case both examiners agreed that there was impairment of $\stackrel{0}{+}$ affective-prosodic comprehension only; however, one of us (PBG) was uncertain under which aprosodia subtype to classify this case (see below).

Each stroke subject had at least one CT scan study during hospitalisation. Scans were performed on the Pfizer FS 200. Each patient's CT scan lesion was mapped onto a right lat- $\omega$ eral or medial-hemispheric template or diencephalic tem- $\overrightarrow{0}$ plate by EDR who was again blinded to all clinical and identifying information. The projection technique developed by $\vec{\omega}$ EDR, is as follows, for producing the hemispheric templates. The lowest cut in the CT scan displaying the most prominent landmarks, that is, mid cerebellum, anterior inferior temporal lobe, gyri recti, orbits, etc, for indicating the angle of the $O$ CT scan is drawn on the template as a baseline. A perpendic- ir ular line is then erected from the baseline to the most rostral of part of the brain template using a right angle triangular $\mathcal{\omega}$ drafting tool. Using an eleven-arm-adjustable-equal-spacing 윽 divider (Charvoz 11-1188), the relative level of each of the remaining CT cuts above the baseline cut is notched on the $\vec{z}$ vertical, and a line is drawn parallel to the baseline using @ parallel ruler. The divider is then adjusted to section the antero-posterior (AP) distance of each CT cut into ten part $\overrightarrow{5} . \overrightarrow{0}$ The AP length and position of the stroke, as measured the points on the divider, is noted. The divider is then expanded to fit the AP diameter of the CT cut represented on the template, and the distance subtended by the stroke is marked out. After all cuts containing the stroke are recorded on the template, the marks are connected to indicate the area and location of the stroke. (This particular projection technique differs from previously published techniques 2526 in two ways: (1) it allows CT lesions to be mapped accurately onto a standard brain template regardless of the actual overall dimension of the imaged brain by isomorphically adjusting for any AP distance or height incongruity between the imaged brain and the template and (2) the templates are true lateral and medial views of the hemisphere so that anatomical relationships are not distorted by the mapping. Superiorly located gyri and lesions on the lateral template, therefore, appear rather small because they are viewed tangentially.) A similar technique is used for mapping the diencephalic lesions.

\section{Results and comments}

There were eight black patients (six men and two $\Omega$ women) and six white patients (two men and four $N$ women) (see table 1). The average age of the subjects was 65.7 years, with a range of 36-82 years. All patients were right-handed. There were two cases of large artery thrombosis, seven cases of cerebral 
The aprosodias: further functional-anatomical evidence for the organisation of affective language in the right hemisphere

Table 1 Patient characteristics*

\begin{tabular}{llllll}
\hline Case & Age & Race & Sex & Stroke mechanism & Site of vascular involvement \\
\hline 1 & 74 & W & F & Embolism & MCA \\
2 & 62 & B & F & Embolism & MCA \\
3 & 74 & W & F & Embolism & MCA \\
4 & 60 & W & F & Embolism & MCA \\
5 & 61 & B & M & Uncertain & MCA \\
6 & 66 & B & M & Large artery thrombosis & MCA \\
7 & 73 & W & F & Embolism & MCA \\
8 & 57 & W & M & Embolism & MCA \\
9 & 67 & B & M & Embolism & MCA \\
10 & 71 & B & F & Larger artery thrombosis & \\
11 & 36 & B & M & Hypertensive intraparenchymal haemorrhage & \\
12 & 82 & W & M & Lobar intraparenchymal haemorrhage & \\
13 & 70 & B & M & Hypertensive intraparenchymal haemorrhage & PCA \\
14 & 66 & B & M & Uncertain & LS \\
\hline
\end{tabular}

*All patients were right-handed.

$\mathrm{B}=$ black.

$\mathbf{W}=$ white

$F=$ female.

$\mathrm{M}=$ male.

MCA $=$ middle cerebral artery territory.

$\mathrm{ACA}=$ anterior cerebral artery territory.

LS = lenticulostriate artery territory

PCA = posterior cerebral artery territory.

Table 2 Summary of affective behaviour

\begin{tabular}{|c|c|c|c|c|c|}
\hline $\operatorname{Case}(s)$ & $\begin{array}{l}\text { Spontaneous affective } \\
\text { prosody \& gesturing }\end{array}$ & $\begin{array}{l}\text { Affective-prosodic } \\
\text { repetition }\end{array}$ & $\begin{array}{l}\text { Affective-prosodic } \\
\text { comprehension }\end{array}$ & $\begin{array}{l}\text { Comprehension of } \\
\text { emotional gesturing }\end{array}$ & Type of aprosodia \\
\hline $\begin{array}{l}1-6^{*} \\
7 \\
8,9 \\
10+ \\
11 \\
12 \\
13,14\end{array}$ & $\begin{array}{l}\mathrm{A} \\
\mathrm{A} \\
\mathrm{N} \\
\mathrm{N} \\
\mathrm{N} \\
\mathrm{N} \\
\mathrm{N}\end{array}$ & $\begin{array}{l}\mathrm{A} \\
\mathrm{A} \\
\mathrm{A} \\
\mathrm{A} \\
\mathrm{N} \\
\mathrm{N} \\
\mathrm{N}\end{array}$ & $\begin{array}{l}\mathbf{N} \\
\mathbf{A} \\
\mathbf{N} \\
\mathbf{A} \\
\mathbf{A} \\
\mathbf{A} \\
\mathbf{N}\end{array}$ & $\begin{array}{l}\mathbf{N} \\
\mathbf{A} \\
\mathbf{N} \\
\mathbf{A} \\
\mathbf{A} \\
\mathbf{N} \\
\mathbf{N}\end{array}$ & $\begin{array}{l}\text { Motor } \\
\text { Global } \\
\text { Conduction } \\
\text { Sensory } \\
\text { Transcortical sensory } \\
\text { Pure affective deafness } \\
\text { Normal }\end{array}$ \\
\hline
\end{tabular}

*Initial evaluations in Case 5 demonstrated a global aprosodia which rapidly evolved over several days into a motor aprosodia.

†Initial evaluations demonstrated a sensory aprosodia which weeks later evolved into a transcortical sensory aprosodia.

$\mathrm{N}=$ normal, $\mathbf{A}=$ abnormal.

embolism and three cases of intraparenchymal haemorrhage (see table 1). Ischaemic stroke mechanism was uncertain in two patients. The sites of vascular involvement were: the middle cerebral artery stem, major divisions or branches (nine cases); lenticulostriate arteries (two cases); anterior cerebral artery (one case); and the posterior cerebral artery (two cases).

\section{Bedside examination of affective behaviour}

In our study population 12 patients had aprosodias (cases 1-12), and two patients had normal examinations of affect (cases 13 and 14). There were six subjects with motor aprosodia (cases 1-6), one with global aprosodia (case 7), two with conduction aprosodia (cases 8 and 9), one with sensory aprosodia (case 10), one with transcortical sensory aprosodia (case 11), and one with pure affective deafness (case 12). Table 2 summarises the affective behavioural features for each patient. Case 10 evolved into a transcortical sensory aprosodia over several weeks after being diagnosed initially as having a sensory aprosodia. Case 5 evolved over several days into a motor aprosodia after first being diagnosed as a global aprosodia. For classification and correlation purposes, he was considered to have a motor aprosodia (see below) since this change occurred during the acute stages of his infarct.

\section{CT Scan correlations}

Motor Aprosodia Figure 1 is a composite template of the six patients diagnosed as having motor aprosodia. CT abnormalities were characterised predominantly by ischaemic infarctions involving the frontal opercula. Some patients had lesions that extended into the anterior parietal opercula (cases 1, 3, 4 and 5) and two patients also had infarctions involving the very anterior portions of the temporal lobe (cases 3 and 4). However, the posterior and superior midtemporal regions were spared in all instances. In one patient (case 2) with a past history of rheumatic heart disease, atrial fibrillation and myocardial infarction, a left occipital infarction, undiagnosed previously, was also noted. In addition, although this subject's overall 
Fig 1 Composite template showing the CT lesions in the 6 patients with motor aprosodia (cases 1-6). Note that no lesion affected the posterior and mid-superior temporal lobe.

speech was flat due to motor aprosodia, she was still able to display extreme emotional behaviour, in particular crying, when she was discussing emotionally charged life events.

In a prior study, Ross ${ }^{16}$ suggested that motor aprosodia was the right hemisphere functional-anatomical counterpart of Broca's aphasia. In our patients with motor aprosodia, the CT lesions were localised predominantly to the right frontal opercula which would be consistent with the left hemisphere lesions associated with Broca's aphasia. ${ }^{27-30}$ These results lend further support to Ross's hypothesis.

Global aprosodia One patient was diagnosed as hav-

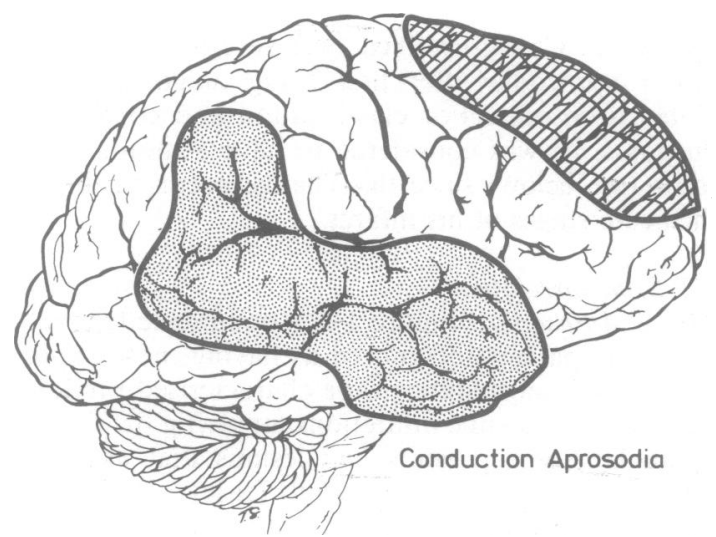

Fig 2 Composite template showing the CT lesions in the 2 patients with conduction aprosodia (cases 8-9). The lesion involving the superior frontal lobe is hatched because this patient was seen 2 months after his initial stroke making clinico-anatomical correlations tenuous. Historically, he most likely had a motor type of aprosodia that evolved into a mild conduction aprosodia.

Fig 3 Template showing the CT lesion in the patient with sensory aprosodia (case 10).

ing a mild global aprosodia. There was no lesion noted on the acute CT scan, which occurs occasionally if the scan is done too early in the course of cerebral infarction. ${ }^{31}$ Unfortunately, a follow-up CT scan was not performed. Since no CT lesion was detected, we cannot make any statements regarding clinico-anatomical correlations.

In our other case of global aprosodia, which rapidly evolved into motor aprosodia after several day (see case 5), a peri-Sylvian fronto-parietal infarctiots was observed. On initial evaluation, he showed onls moderate difficulties with affective comprehension: The CT abnormality correlated with the predicted site of involvement for motor aprosodia. Reversible temporal lobe ischaemia, undetectable by $\mathrm{CT}$, may explain the initial clinical presentation.

Conduction Aprosodia CT lesions in two patients with conduction aprosodia are shown in fig 2 . This type of aprosodia was predicted by Ross ${ }^{1624}$ but not encountered previously. Case 8 (stippled lesion) had an extensive infarction involving the temporal and parietal lobes. Although one would have predicted a sensory aprosodia based upon prior observations, ${ }^{16}$ this was not found. This preliminary finding suggests that the anatomical locus of injury for conduction aprosodia may be as diverse or as wide spread as that of its left hemisphere functional counterpart conduction aphasia. ${ }^{32}{ }^{33}$ In the left hemisphere, pathological lesions causing conduction aphasia have been demonstrated to involve the supramarginal and insular cortex and underlying white matter, the dominant auditory association cortex, or a combination of the two sites. Similarly, the anatomical locus of injury for conduction aprosodia may include homologous right temporal and parietal brain regions which mirror those encountered in the left hemisphere for conduction aphasia. 
The aprosodias: further functional-anatomical evidence for the organisation of affective language in the right hemisphere
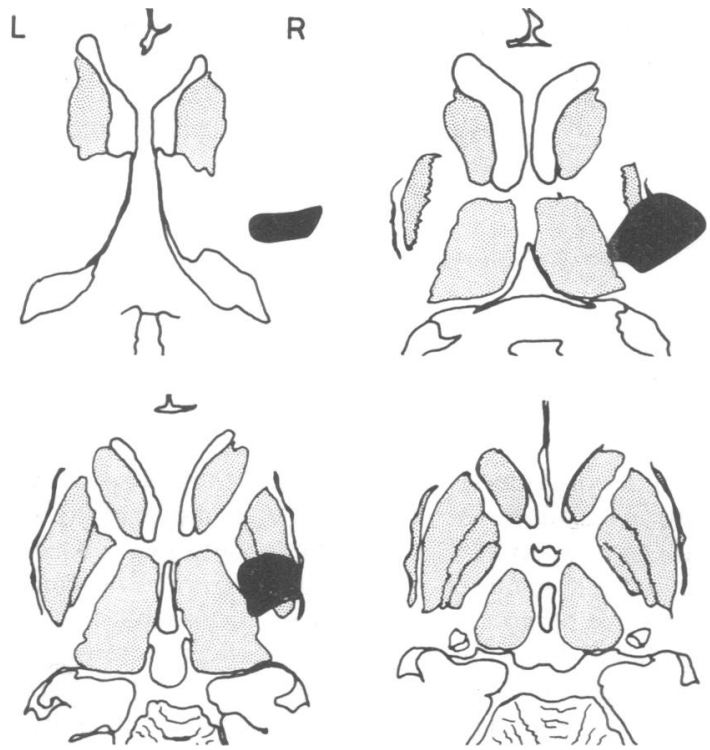

Fig 4 Template showing the distribution of the diencephalic haemorrhage found on CT in the patient with transcortical sensory aprosodia (case 11).

Although case 9 had elements of a conduction aprosodia, the deficits in affective repetition were minimal. This patient was examined 2 months after the stroke and history gathered from the family suggested that he initially had marked flattening of speech which resolved over time. Therefore, his lesion is mapped on the template with hatch marks since we believe his mild conduction aprosodia most likely evolved from a motor type of aprosodia. Transposition of the latter lesion onto the left hemisphere

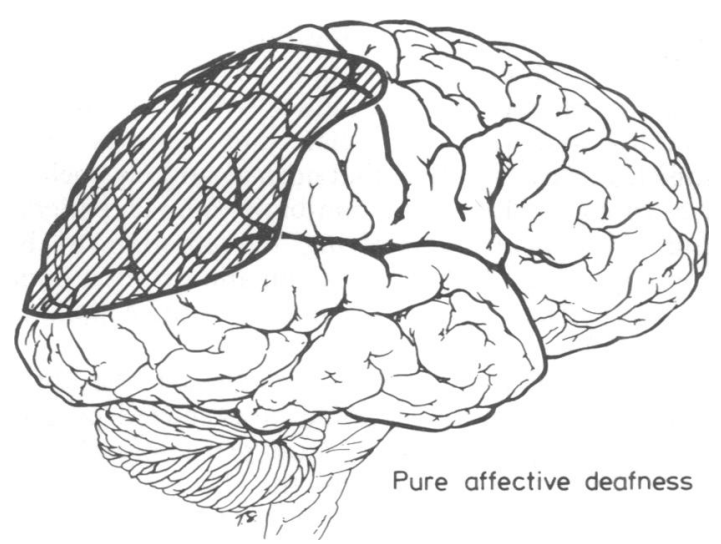

Fig 5 Template showing CT lesion associated with pure affective deafness (case 12). The lesion is hatched since it was a haemorrhage with tracking oedema making clinico-anatomical correlations tenuous. would be expected to result in a transcortical motor aphasia. ${ }^{3435}$

Sensory aprosodia The CT lesion in one patient with sensory aprosodia is shown in fig 3 . A temporoparietal infarction, the predicted site of injury for sensory aprosodia, ${ }^{16}$ is observed. This is also the site in the left hemisphere most commonly associated with Wernicke's aphasia. ${ }^{2728}$ On follow-up examination several weeks later a transcortical sensory aprosodia was noted. This example of improvement in affective-prosodic repetition is reminiscent of improvement in speech repetition that can be observed during the recovery phase of certain aphasias. ${ }^{36}$

Transcortical sensory aprosodia The one patient with transcortical sensory aprosodia had a deep haemorrhage involving the right posterior neostriatum and posterior limb of the internal capsuie, producing only a slight mass effect (fig 4). The subcortical focus of injury on CT scan in this case is comparable to the sites of injury reported recently for transcortical aphasias. ${ }^{3738}$ In addition, transcortical motor aprosodias have also been encountered following right basal ganglia injury suggesting, as with aphasia, that language has both neocortical and subcortical representation. ${ }^{161724}$

Pure affective deafness One patient was diagnosed as having pure affective deafness. The CT scan (fig 5) showed a lobar haemorrhage involving the occipitoparietal region with oedema extending more anteriorly. The lesion and oedema are shown in fig 5 using hatch marks, since the case is not really appropriate for making firm clinical pathological correlation because of the nature of the lesion. This aprosodia subtype has never been described in isolation although the combination of motor aprosodia with pure affective deafness from a lesion involving the right frontal and mid-anterior temporal opercula has been reported. ${ }^{16}$ Its aphasia counterpart, pure word deafness, is usually the result of lesions involving the left mid-anterior temporal opercula. ${ }^{39-42}$

Normal affective behaviour Two patients had no detectable abnormality at bedside testing of affective behaviour. CT scans (fig 6a and b) in these two patients revealed: (1) a right diencephalic haemorrhage involving the superior-posterior putamen, superior lateral thalamus and the posterior limb of the internal capsule (case 13) and 2) an inferiormedial occipital infarction that spared the right periSylvian opercular structures, the angular gyrus and splenium of the corpus callosum (case 14). The absence of affective language impairment in these cases may reflect lack of involvement of critical affective language loci or left hemisphere dominance for this neural process. In case 14 , the lesion was in a region that one might have expected loss of visual 


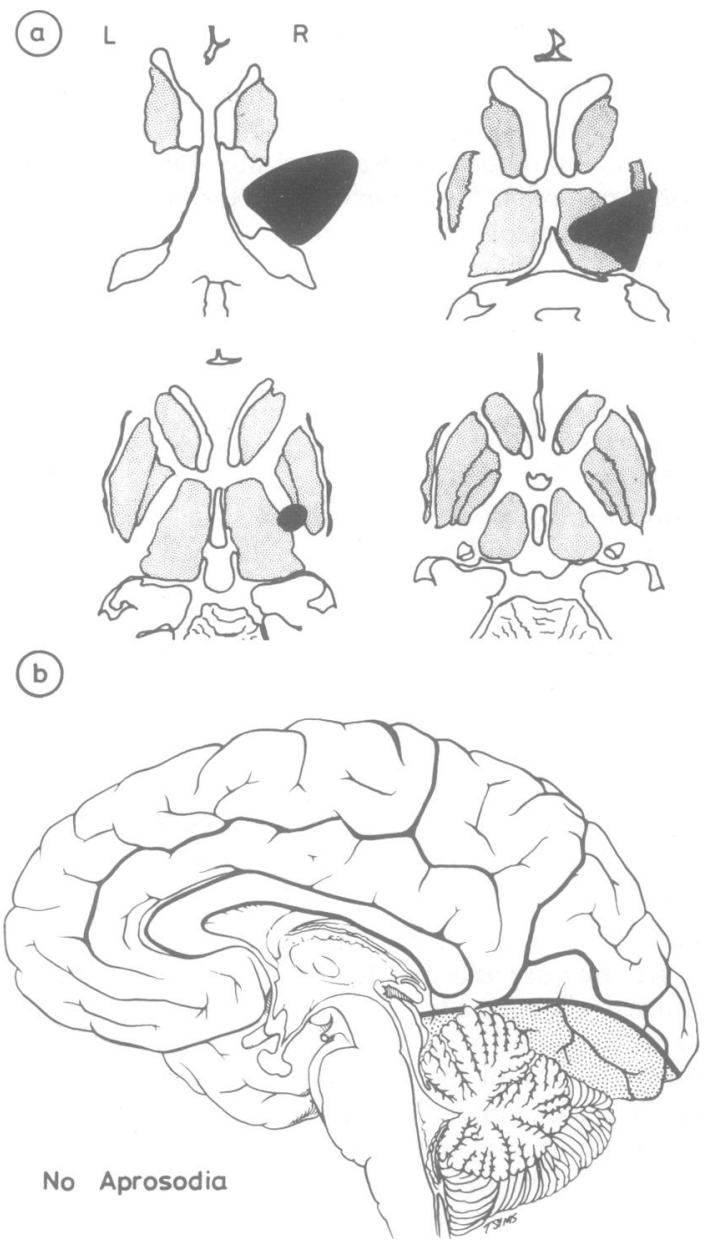

Fig 6 (a) Template of one of the patients with no disturbances in affective modulation who suffered a diencephalic haemorrhage (case 13). (b) Template showing the lesion in the second patient with normal modulation of affective language (case 14). The lesion spared the peri-Sylvian structures, angular gyrus, and the splenium of the corpus callosum.

naming and comprehension of emotional gesturing similar to the left hemisphere syndrome of alexia without agraphia. ${ }^{27}$ However, the lack of supracalcarine and callosal involvement probably preserved the critical peristriate and visual interhemispheric connections to allow visual recognition (right hemisphere) and visual naming (left hemisphere) of emotional gesturing. Crossed dominance in right handers has been described previously in aphasia. ${ }^{43-45}$ In such cases, the neural processes governing propositional language are located in the right rather than in the left hemisphere. Similarly, the neural processes regulating affective prosody in some individuals may reside in the left rather than the right hemisphere. Although crossed aprosodia has not been reported previously, we speculate that its frequency of occurrence parallels that of its functional counterpart of crossed aphasia. ${ }^{43-45}$ Further observations will be required to substantiate this hypothesis.

\section{Discussion}

Recent studies of affective language have focused attention on the right hemisphere. Heilman ${ }^{11}$ and colleagues provided evidence that right temporo-parietal lesions caused defects in the comprehension of affective speech. Tucker ${ }^{12}$ and colleagues observed that right temporo-parietal lesions not only caused affective comprehension deficits in patients but also rendered them unable to evoke affective intonation on a repetition task. Ross and Mesulam ${ }^{14}$ described loss of spontaneous affective behaviours in patients with right frontal opercula lesions even though these patients could feel emotions inwardly and comprehend affective behaviours in others. Based on their patients and the work of Heilman ${ }^{11}$ and associates, they proposed that the right hemisphere dominantly modulates affective language and behaviour and thaf this modulation is organised in an analogous fashiop to the left hemisphere's role in propositional lans. $\overrightarrow{0}$ guage. In a follow-up study, Ross ${ }^{16}$ provided add tional confirmatory evidence of the functionalanatomical organisation of the affective components of language in the right hemisphere. The resulting disturbances of affective modulation for which he coined the term aprosodias, were classifiable and characterised by distinct anatomic loci of injury.

The bedside examination and diagnosis of the aprosodias are easy once the proper technique for making the observations is mastered. With just a minimum of practice the first author (PBG) was able to wilfully modulate his voice and gestures with sufficient clarity of affect that normal subjects, including young children and non-brain injured patients had no difficulty identifying the emotion to be communicated. Thus, this examination can be done at the bedside just as one does a routine aphasia examination.

In addition to being easily diagnosed, the aprosodias are common, as would be predicted by previously published clinical ${ }^{1416}$ and physiological studies. $^{13}$ In our series 12 of the 14 consecutively o examined patients with right hemisphere stroke had an aprosodia. Over the same 6 month period, 15 consecutive patients with left hemisphere stroke were admitted to the Michael Reese Hospital and evaluated by PBG. Of these, 12 had aphasic syndromes. 
The aprosodias: further functional-anatomical evidence for the organisation of affective language in the right hemisphere

These data suggest that the aprosodias are as common as the aphasias.

We have shown, as have others, ${ }^{11121416-24}$ that various disturbances of affective language may result following focal right hemisphere injury either from predominantly cortical or diencephalic lesions ${ }^{1617}$ and that recovery patterns, similar to the aphasias, may also occur. ${ }^{16}$ Our data, therefore, lend further support to the hypothesis that the organisation of affective language in the right hemisphere mirrors that of propositional language in the left hemisphere. Additionally, we have encountered two aprosodia subtypes not reported previously (conduction aprosodia and pure affective deafness), and have observed that extreme emotional displays congruent with the patient's feeling state, for example crying in case 2 in the presence of motor aprosodia, may occur in the context of loss of graded spontaneous affective behaviour. The latter observation coupled with prior evidence ${ }^{1619}$ suggests that emotional experience and the display of extreme emotions are dissociable from the expression of graded affective behaviour. ${ }^{24}$ This implies, therefore, that the neuroanatomical substrates for these behaviours have different localisations. Current data suggest that extreme emotional displays are organised outside the right neocortex probably by the temporal limbic system, basal forebrain and diencephalon ${ }^{24}$ while emotional experience seems to be associated with temporal limbic structures, in particular the amygdala and hippocampus. ${ }^{46}$

This work was supported in part by NIH Contract N01-NS-2-2399 and a grant from the AMOCO Foundation.

\section{References}

1 Hughlings-Jackson J. On affections of speech from disease of the brain. Brain 1915;38:106-74 (in 3 parts).

2 Monrad-Krohn GH. Dysprosody or altered "melody of language". Brain 1947;70:405-15.

3 Monrad-Krohn GH. The prosodic quality of speech and its disorders. Acta Psychiatr Neurol Scand 1947;22:255-69.

4 Monrad-Krohn GH. Altered melody of language ('dysprosody') as an element of aphasia. Acta Psychiatr Neurol (Supp.) 1947;46:204.

5 Monrad-Krohn GH. The third element of speech: prosody and its disorders. In: Halpern L (ed.) Problems of Dynamic Neurology. Jerusalem, Hebrew University Press 1963:101-17.

6 Kimura D. Functional asymmetry of the brain in dichotic listening. Cortex 1967;3:163-78.

7 Haggard MP, Parkinson AM. Stimulus and task factors as determinants of ear advantages. $Q J$ Exp Psychol 1971;23:168-77.

8 Blumstein S, Goodglass $\mathrm{H}$. The perception of stress as a semantic cue in aphasia. J Speech Hear Res 1972;15(4):800-6.
9 Wechsler AF. The effect of organic brain disease on recall of emotionally charged versus neutral narrative texts. Neurology 1973;23:130-5.

10 Schwartz GE, Davidson RJ, Maer F. Right hemisphere lateralization for emotion in the human brain: interactions with cognition. Science 1975;190:286-8.

11 Heilman KM, Scholes R, Watson RT. Auditory affective agnosia: disturbed comprehension of affective speech. J Neurol Neurosurg Psychiatry 1975;38:69-72.

12 Tucker DM, Watson RT, Heilman KM. Discrimination and evocation of affectively intoned speech in patients with right parietal disease. Neurology 1977;27:947-50.

13 Larsen B, Skinhoj E, Lassen NA. Variations in regional cortical blood flow in the right and left hemispheres during automatic speech. Brain 1978;101:193-209.

14 Ross ED, Mesulam MM. Dominant language functions of the right hemisphere? Prosody and emotional gesturing. Arch Neurol 1979;36:144-8.

15 Cione M, Wapner W, Gardner H. Sensitivity to emotional expressions and situations in organic patients. Cortex 1980;16:145-58.

16 Ross ED. The aprosodias. Functional-anatomic organization of the affective components of language in the right hemisphere. Arch Neurol 1981;38:561-9.

17 Ross ED, Harney JH, deLacoste-Utamsing D, et al. How the brain integrates affective and propositional language into a unified behavioural function: hypothesis based on clinicoanatomic evidence. Arch Neurol 1981;38:745-8.

18 Weintraub S, Mesulam MM, Kramer L. Disturbances in prosody. A right hemisphere contribution to language. Arch Neurol 1981;38:742-4.

19 Ross ED, Rush AJ. Diagnoses and neuroanatomical correlates of depression in brain-damaged patients. Arch Gen Psychiatry 1981;38:1344-54.

20 Ross ED. The divided self. The Sciences 1982 (Feb):8-12.

21 Kent RD, Rosenbek JC. Prosodic disturbances and neurologic lesion. Brain Lang 1982;15:259-91.

22 Hughes CP, Chan JL, Su MS. Aprosodia in Chinese patients with right cerebral hemisphere lesions. Arch Neurol 1983;40:732-6.

23 Speedie LJ, Coslett HB, Heilman KM. Repetition of affective prosody in mixed transcortical aphasia. Arch Neurol 1984;41:268-70.

24 Ross ED. Right hemisphere's role in language, affective behaviour and emotion. Trends in Neurosciences 1984;7:342-6.

25 Mazzocchi F, Vignolo LA. Computer assisted tomography in neuropsychological research. A simple procedure for lesion mapping. Cortex 1978;14:136-44.

26 Luzzatti C, Scotti G, Gattoni A. Further suggestions for cerebral CT-localization. Cortex 1979;15:483-90.

27 Benson DF. Aphasia, Alexia and Agraphia. New York: Churchill Livingstone, 1979.

28 Kertesz A. Aphasia and Associated Disorders. New York: Grune and Stratton Inc, 1979.

29 Mohr JP. Broca's area and Broca's aphasia. In: Whitaker H, Whitaker HA, (eds.): Studies in Neurolinguistics. New York: Academic Press 1976, Vol 1, 201.

30 Mohr JP, Pessin MS, Finklestein S, Funkenstein H, 
Duncan GW, Davis KR: Broca aphasia: pathologic and clinical. Neurology 1978;28:311-24.

31 Davis KR, Kistler JP, Buonanno FS. Clinical neuroimaging approaches to cerebrovascular diseases. In: Buonanno FS (ed). Neurologic Clinics 1984;2:655-65.

32 Benson DF, Sheremata WA, Bouchard R, Segarra JM, Price D, Geschwind N. Conduction aphasia. A clinicopathologic study. Arch Neurol 1973;28:339-46.

33 Damasio H, Damasio AR. The anatomical basis of conduction aphasia. Brain 1980;103:337-50.

34 Masdeu JC, Schoene WC, Funkenstien H. Aphasia following infarction of the left supplementary motor area. Neurology 1978;28:1220-3.

35 Racy A, Jannotta FS, Lehner LH. Aphasia resulting from occlusion of the left anterior cerebral artery. Arch Neurol 1979;36:221-4.

36 Kertesz A. Recovery and treatment. In: Heilman KM, Valenstein E, (eds.) Clinical Neuropsychology. New York: Oxford University Press 1979:503-34.

37 Naeser MA, Alexander MP, Helm-Estabrooks N, Levine HL, Laughlin SA, Geschwind N. Aphasia with predominantly subcortical lesion sites. Description of three capsular/putaminal aphasia syndromes. Arch Neurol 1982;39:2-14.
38 Damasio AR, Damasio H, Rizzo M, Varney N, Gersh F. Aphasia with non-hemorrhagic lesions in the basal ganglia and internal capsule. Arch Neurol 1982;39:15-20.

39 Barrett AM. A case of pure word-deafness with autopsy. J Nerv Ment Dis 1910;37:73-92.

40 Albert ML, Bear D. Time to understand. A case study of word deafness with reference to the role of time in auditory comprehension. Brain 1974;97:373-84.

41 Spreen O, Benton AL, Fincham RW. Auditory agnosia without aphasia. Arch Neurol 1965;13:84-92.

42 Gazzaniga MS, Glass AV, Sarno MT, Posner JB. Pure word deafness and hemispheric dynamics: a case history. Cortex 1973;9:136-43.

43 Zangwill OL. Speech and the minor hemisphere. Acta Neurol Psychiatr Belg 1967;67:1013-20.

44 Brown JW, Wilson FR. Crossed aphasia in a dextral. A case report. Neurology 1973;23:907-11.

45 Zangwill OL. Two cases of crossed aphasia in dextrals. Neuropsychologia 1979;17:167-72.

46 Gloor P, Olivier A, Quesney LF, Andermann F, Horowitz $\mathrm{S}$. The role of limbic system in experiential phenomena of temporal lobe epilepsy. Ann Neurol 1982;12:129-44. 